\title{
Using a research coach to enhance evidence-based practice integration in undergraduate nursing
}

\author{
Melba Sheila D'Souza* \\ School of Nursing, Thomspon Rivers University, BC, Canada
}

Received: April 24, 2021

Accepted: July 27, 2021

Online Published: August 24, 2021

DOI: $10.5430 /$ jnep.v11n12p73

URL: https://doi.org/10.5430/jnep.v11n12p73

\begin{abstract}
Background and Objective: Coaching contributes to the understanding and application of knowledge in nursing practice. This study aims to examine the implementation of a research coach to enhance evidence-based practice integration in undergraduate nursing.

Methods: Design: This study used a quasi-experimental non-equivalent post-test-only design. Settings and participants: Forty second-year undergraduate nursing students were invited to participate in the study at a public university in 2019. Methods: The evidence-based practice (EBP) questionnaire was used, and the primary outcomes were attitudes, skills, and capabilities of EBP. The undergraduate students worked with a third-year level research coach to engage in evidence-based nursing using clinical case studies.

Results: The findings expressed the students' readiness to capture, select, and organize their critical thinking skills through case studies and online discussion. Students perceived that they needed versatile skills in the interpretation and application of evidence-based nursing.

Conclusions: A research coach played an essential role for novice student nurses in improving decision-making skills and transition to practice in this setting. The research coach model enables critical thinking and problem-solving skills through interaction and case studies.
\end{abstract}

Key Words: Evidence-based nursing, Education, Students, Undergraduate, Coach, Research, Practice, Nursing

\section{INTRODUCTION}

\subsection{Evidence-based nursing in education and practice}

Baccalaureate programmes prepare a generalist nurse for entry to practice by progressively developing research, critical enquiry, and evidence skills. ${ }^{[1]}$ Undergraduate nursing fosters critical thinking and research abilities that use evidence to inform nursing practice. ${ }^{[1]}$ Entry-level registered nurses are prepared to participate in changes that promote evidence-based nursing practices in the client services. ${ }^{[2]}$ Evidence-based practice (EBP) is one of the core competencies for nurses which enables them to make decisions based on scientific evidence. The goal of EBP in undergraduate nursing is to prepare students by translating the best available evidence into clinical practice. Therefore, knowledge acquisition, critical thinking, and problem-solving skills are needed to translate EBP in nursing education.

EBP education plays a critical role in the acquisition of competencies in nursing students to have adequate knowledge, skills, and attitudes to integrate best evidence in nursing. ${ }^{[3]}$ Within the context of nursing, EBP is defined as a "problemsolving approach to the delivery of healthcare that integrates the best evidence from well-designed studies and patient care data and combines it with [clinical expertise and] patient pref-

*Correspondence: Melba Sheila D’Souza; Email: mdsouza@tru.ca; Address: School of Nursing, Thomspon Rivers University, BC, Canada. 
erences and values". ${ }^{[4]}$ The steps of EBP include formulating clinical questions, searching for evidence, critically appraising evidence, and applying the findings to clinical practice. ${ }^{[5]}$ These steps enable students to develop knowledge and to use these empirical findings to recommend changes in practice. ${ }^{[6]}$ Student engagement in EBP allows for collaborative learning, interaction with faculty, and enriched learning experiences. Involvement of a Research coach may be effective to increase students' confidence and knowledge to guide decision making compared to usual teaching practice. Hence, this study examined the implementation of a research coach to enhance evidence-based practice integration in client care with undergraduate nursing students.

\subsection{Scholarship}

Teaching EBP may significantly impact students' skills and application of EBP. ${ }^{[7]}$ Nursing students need adequate knowledge and competence to effectively implement EBP changes. ${ }^{[8]}$ There has been a positive attitude towards EBP among Jordanian nursing students, ${ }^{[8]}$ and a positive correlation with the use of EBP among Australian undergraduate students. ${ }^{[9]}$ The selection of teaching strategies is based on the need for students' engagement and problem solving in acquiring confidence and knowledge. Teaching nursing students' knowledge and skills related to EBP can help boost their self-efficacy to use evidence in their practice. ${ }^{[7]} \mathrm{EBP}$ knowledge and skills are expected to increase with advancing academic levels due to mastery of knowledge, repeated exposure to research utilization, and experience of EBP. ${ }^{[3]}$ Studies of EBP education have emphasised enquiry-based and critical appraisal skills..$^{[10,11]}$

Higher education levels and greater clinical experience are associated with increased self perceived EBP competence and clinical decision making in students. ${ }^{[12,13]}$ Hence, nursing students require confidence in their ability to engage with EBP in their practice. Challenges in evidence gathering skills in accessing, utilizing, and appraising EBP information are the main themes in understanding the importance of evidence for practice. ${ }^{[14]}$ For example, undergraduate nursing students had difficulty comprehending the relevance of research while learning clinical psychomotor skills, ${ }^{[15]}$ while lack of time, knowledge, and experience of innovative teaching approaches was identified as barriers to EBP. ${ }^{[16]}$ These studies have shown that nursing students perceive difficulty in comprehending EBP and report the limited applicability of EBP to their clinical practice. Hence there is a need to increase the perception of relevance and transfer requisite EBP skills in younger cohorts through coaching.

A coach is defined as an "experienced person who shares their knowledge or helps someone achieve goals to facili- tate the learning process in their role" ${ }^{[17]}$ while developing a mutual relationship ${ }^{[18]}$ Coaching is defined as "one-to-one conversations that focus on enhancing learning and developing a sense of responsibility". A coach facilitates questioning, active listening, and appropriate challenges in a supportive climate with a trainee (student). ${ }^{[19]}$ Coaching through experience and knowledge supports trainee with psychological and social help, provided through a positive relationship. ${ }^{[20]}$ Some studies have found that coaches and trainees form close relationships, increase the sense of responsibility, advocate for role models, and positively affect the coach-trainee relationship. ${ }^{[18]} \mathrm{A}$ few studies ${ }^{[21]}$ have positively impacted learning outcomes. ${ }^{[22,23]}$ Furthermore, student coaching has led to improvements in performance and well-being ${ }^{[24,25]}$ and has also improved self-motivation. ${ }^{[26]}$ Junior students who worked with senior students in a research coach relationship reported experiencing improved coping skills, resilience, hardiness, and hope. ${ }^{[27]}$ Peer student coaching has indicated that students can be trained to coach one another successfully. ${ }^{[28,29]}$ There are very few studies on developing and using a research coach to enhance the use of EBP in teaching nursing students. However, there is a gap in the literature that addresses the implementation and evaluation of research coaches in improving the integration of EBP in undergraduate students in Canada.

\subsection{Aim}

The study aims to examine the implementation of a research coach to enhance evidence-based practice integration in undergraduate nursing.

\section{METHOD}

\subsection{Ethics}

Ethical approval was obtained from the institution's research ethics board to conduct the study. Permission to access nursing students was granted by the dean of the school of nursing. The principal investigator explained the study, eligibility, consent, confidentiality in research, and anonymity in handling the data. Participants could withdraw from the study at any time without hindrance to their learning, success, and performance in the course.

\subsection{Research coach model intervention}

A quasi-experimental non-equivalent post-test-only design as used with a research coach model introduced to facilitate an inquiry-based approach in a nursing course at a public university. The research coach was implemented with a thirdyear undergraduate nursing student called as the research coach, who was coached, trained, and supervised to facilitate EBP to second-year undergraduate students. The health and healing course was redesigned with a social innovative 
teaching strategy using a research coach for assisting and coaching students in EBP. The research coach model intervention intended to use a case study approach to facilitate understanding and enrich experiences, thus modifying students' learning behaviours in the Fall semester of 2019 for 15 weeks. Learning activities, core readings, and online discussions on a learning management system (Moodle) were included in the research coach model. The faculty taught direct or face-to-face class, had interactive clinical case studies using EBP articles and implemented the research coach model. Clinical case studies that embedded information literacy and problem-solving exercises were used to engage peer groups and online discussions. The results of the research coaching included the development of a focused EBP scholarly paper. Self-reflections of students were balanced with guided feedback through videos. It was challenging to deliver the research coach outside the class due to increase in academic and student curricular activities outside the classroom environment. The approved research and ethics protocols were used to maintain the quality of the research coach delivery and field notes were taken. The faculty and research coach assessed the integrity and fidelity of the intervention to be rigorous and consistent with the research coach model teaching strategy.

\subsection{Sampling procedures}

A purposive sample with a total class size of 40 second-year undergraduate nursing students who were actively enrolled in the health and healing course section was used in the study.

\subsubsection{Research design}

This research study consisted of a quasi-experimental nonequivalent post-test-only design. This design was used in a single classroom setting, where randomization and control group could not be conducted for ethical reasons. The participants in one group were exposed to research coach model and the differences between the participants were observed. A difference in the single group may be caused by the effect of the research coach model or any confounding variables.

\subsubsection{Measurement}

The study's primary outcomes were the attitudes, skills, uses, barriers, and facilitators of EBP. The EBP questionnaire (EBPQ) was used with permission. ${ }^{[30]}$ The EBPQ is designed to gather information and opinions on the use of EBP among nursing students using a seven-point rating scale. The EBPQ's behavioural statements (31 items) were: practice to an individual patient's care in clinical and in response to a gap in the knowledge of EBP (6 items, ranging from never to frequently); use and attitude of EBP (4 items, ranging from most to least important); skills and capability in EBP (14 items, ranging from poor to best); and implementation of a research coach (7 items).

The Research Coach Survey (RCS) was developed by the investigator and research coach and consisted of open-ended items (6 items) based on perceptions and experiences of the research coach model. The RCS was validated and found to be reliable $(\mathrm{r}=0.78)$. The final $\mathrm{RCS}$ included questions such as 'What helped you engage with the research coach to learn EBP in your class?'; 'What kind of barriers did you face when interacting with the research coach to learn EBP in your class?'; 'Provide any constructive feedback regarding your use of a research coach'; 'Provide any beneficial suggestions for ways that would enhance your learning of EBP'; 'Describe your experiences with learning and applying EBP in the course'; and 'Explain your challenges and how you overcame them while understanding and using EBP in the course'. The validity of the EBPQ and RCS instruments (consistency) was confirmed with inter-rater reliability in this study.

Demographic information consisted of previous education, gender, age, and ethnicity.

\subsection{Recruitment}

Written consent was obtained from all participants. Participants were given an introduction letter and an invitation to participate in the study. Participants who volunteered were provided with a study package, including a cover letter, informed consent for access to Moodle, and survey questionnaires. Confidentiality and data anonymity (coded using pseudonyms) were maintained. The post-test EBPQ and RCS was administered before the end of 15 weeks. The duration of the surveys varied from 35-45 minutes conducted during the class time. The collected data were master coded, sorted, and stored separately. No data were collected from the research coach.

\subsection{Statistics and data analysis}

Quantitative data were analysed using SPSS version 25 (IBM Corp, 2017). Qualitative data of participants' comments were typed into a document and analysed using qualitative content analysis. The investigator transcribed the surveys verbatim for this study. Content analysis was used to analyze each transcript for relationships between the themes and subthemes. The investigator read and hand-coded the text of each transcript to identify repeated phrases and ideas that were then organised and grouped into categories. The investigator reviewed the transcripts multiple times to explore categories, and the data were organised and integrated into themes after verifying with the research coach. The findings were sent to participants for validation of data findings to confirm the contextual meaning. 


\section{RESUlts}

\subsection{Participant's characteristics}

Forty students were enrolled in the study, and twenty-one (53.8\%) completed the survey. Most of the participants were female $(20 ; 95.2 \%)$, one was male $(4.8 \%)$. All were higher secondary students $(85.7 \%)$, while three $(14.3 \%)$ were mature students in the undergraduate nursing programme. Eighteen $(85.7 \%)$ of the students were $20-29$ years, and three $(14.9 \%)$ were above 29 years.

Table 1. Descriptive of evidence-based practice and research coach model $(\mathrm{N}=21 / 40)$

\begin{tabular}{|c|c|c|c|}
\hline & $\begin{array}{l}\text { Evidence Based Practice (EBP) } \\
\text { Minimum-Maximum: 1-7 }\end{array}$ & Mean $(\overline{\mathbf{x}})$ & $\begin{array}{l}\text { Standard Deviation } \\
\text { (SD) }\end{array}$ \\
\hline A & \multicolumn{3}{|c|}{ Practice in relation to an individual patients' care in clinical and in response to a gap in knowledge of EBP } \\
\hline 1.1 & Formulate clear answer & 5.19 & 1.14 \\
\hline 1.2 & Tracked relevant evidence & 5.0 & 1.02 \\
\hline 1.3 & Critically appraised & 4.0 & 1.67 \\
\hline 1.4 & Integrated evidence & 4.52 & 1.5 \\
\hline 1.5 & Evaluated outcomes & 5.52 & 1.47 \\
\hline 1.6 & Shared information & 4.1 & 1.66 \\
\hline $\mathrm{B}$ & Use and attitude of EBP & & \\
\hline 2.1 & Workload great vs new evidence & 3.33 & 1.13 \\
\hline 2.2 & Recent clinical vs welcome questions & 5.33 & 1.46 \\
\hline 2.3 & EBP vs fundamental & 5.1 & 1.72 \\
\hline 2.4 & Trusted methods vs Practice changed & 5.05 & 1.59 \\
\hline $\mathrm{C}$ & Skills and capability in EBP & & \\
\hline 3.1 & Research skills & 4.24 & 1.02 \\
\hline 3.2 & IT skills & 3.86 & 1.52 \\
\hline 3.3 & Practice Skills & 4.7 & 1.14 \\
\hline 3.4 & Converting information into Research Question & 4.2 & 1.47 \\
\hline 3.5 & Awareness of Major Information & 4 & 1.26 \\
\hline 3.6 & Identifying Gaps & 4.86 & 1.21 \\
\hline 3.7 & Retrieving Articles & 4.67 & 1.13 \\
\hline 3.8 & Analyzing evidence against set standards & 4.3 & 1.05 \\
\hline 3.9 & Validity & 4.14 & 1.04 \\
\hline 3.10 & Useful Information & 4.45 & 1.07 \\
\hline 3.11 & Applying Information to Individual Cases & 4.57 & 1.05 \\
\hline 3.12 & Knowledge Transfer & 4.62 & 1.21 \\
\hline 3.13 & Dissemination & 4.67 & 1.36 \\
\hline 3.14 & Reviewing own practice & 4.86 & 1.08 \\
\hline $\mathrm{D}$ & Implementation of research coach & & \\
\hline 4.1 & Benefited student & 3.39 & 1.46 \\
\hline 4.2 & Comfortable with EBP & 2.88 & 1.37 \\
\hline 4.3 & Availability & 3.59 & 1.33 \\
\hline 4.4 & Comfortable approaching research coach & 3.53 & 1.61 \\
\hline 4.5 & Future research coach for EBP projects & 4.35 & 1.71 \\
\hline 4.6 & Research coach answered questions clearly & 3.65 & 1.88 \\
\hline 4.7 & Research coach helped understand EBP & 3.47 & 1.79 \\
\hline
\end{tabular}




\subsection{Post-intervention}

\subsubsection{Research coach model outcomes}

Participants were favourable towards EBP and 'strongly agreed' that they evaluated outcomes $(\bar{x}=5.5, \mathrm{SD}=1.5)$ and could formulate clear answers $(\bar{x}=5.2, \mathrm{SD}=1.1)$ about an individual patient's care in clinical practice and response to a gap in the knowledge of EBP (see Table 1). For the level of EBP activity when commencing the research coach model, most participants, preferred future research for EBP projects $(\bar{x}=4.4, \mathrm{SD}=1.7)$. Research coach answered EBP questions clearly to the trainees $(\bar{x}=3.7, \mathrm{SD}=1.9)$ and helped the trainees understand $\operatorname{EBP}(\bar{x}=3.5, \mathrm{SD}=1.8)$. A moderate level of activity was reported by some participants, who perceived that being comfortable with $\mathrm{EBP}(\bar{x}=2.9, \mathrm{SD}$ $=1.4)$, and the research coach benefited students $(\bar{x}=3.4$, $\mathrm{SD}=1.5$; Table 1). Some participants identified a lack of time and inadequate skills in searching and interpreting the literature as barriers to EBP uptake.

\subsubsection{Research coach model themes}

Three core themes were conceptualised from the students' responses after the research coach model intervention: (1) engaging in active learning and sharing knowledge, (2) guidance and interacting with a research coach, and (3) knowledge exchange and application of EBP.

Theme 1. Engaging in active learning and sharing knowledge

Some participants were keen to ask clinical questions, find relevant evidence, and use evidence when engaging in selflearning and online learning. Engaging in learning case studies was appropriate and involved complex health and healing conditions, which helped inform decision-making. The catalyst for teaching learning was an e-learning platform that used positive engagement between students and learning activities. One student stated, "I was concerned about using EBP, but this learning experience helped me see how meaningful it is to learn EBP. The Moodle course provided the EBP articles and resources to learn. Pre-readings and articles available on Moodle are comforting, helpful, and help us to see strong evidence for basing our clinical practice on EBP" [S2]

Another student stated that reinforcing EBP activities was valuable, saying, "I engage in my learning and conversing with faculty and peers. I became observant of engaging in the elements of EBP in the classroom. It was useful to apply EBP steps on Moodle to work out our EBP scholarly papers. It was helpful to find online links to EBP resources and quizzes on Moodle". [S12]

The importance of knowledge, EBP, and critical thinking was perceived as essential factors in teaching. Some participants

Published by Sciedu Press were keen to share knowledge and enhance their learning experiences when interacting with faculty in the learning process. The students expressed how they conformed to the learning expectations to make decisions in the EBP case studies. One student observed that they could share knowledge, saying that "I think there is a balance of knowledge and understanding to find the right connection between knowledge and practice and to know how to analyse excerpts in the EBP articles". [S8]

One of the students expressed, "I gained skills from asking questions like what and why I am doing this, and this is the best thing to do in my search for knowledge and learning. They must guide research by talking to a knowledgeable person. Case studies and online discussions worked well for me and having health professionals and patient demographic speakers come into class has helped me in my learning". [S11]

Research coach model offered diverse groups of students the chance to exchange ideas, ask questions, and discuss research that resulted in opportunities for individual learning. Preparing students to use EBP could positively influence student nurses' practice. Participants perceived that engaging in EBP concepts was positive, helpful, and meaningful to them. Another student remarked that "I think it helped me to find evidence to back up the questions from a patient's perspective, and it helped with my ability to find literature to support my learning and engaging in case studies. I had opportunities to share my knowledge, ask questions, and influence my learning. More one-on-one time and exposure to interesting learning activities always help us. I asked the teacher questions about EBP and was able to understand the process". [S14]

\section{Theme 2. Guidance and interacting with a research coach}

Students viewed the research coach as positive support in learning EBP when locating, reading, and critiquing evidence. The research coach provided examples of evidence to critical questions in patient care practice reflected as a change in their critical thinking. The students expressed that they had mixed feelings of being both anxious and thrilled about interacting with the research coach to work with EBP case studies. One of the students stated that "I enjoyed being part of the learning with the research coach and seeing how dedicated the coach was in EBP. Research coaches being present during class time are more beneficial than contacting them via email or social media. The research coach came to class to engage with us in our case study group work". [S20]

The student expected that the experience of a research model would help them prepare for working with EBP concepts. 
Furthermore, one student realized that the experience would inform them of the use of EBP in learning, saying, "I participated with the research coach in my choice of a group project and to gain an impression of the concept of EBP and focus on the connections. I met the research coach through the faculty and undergraduate research award programme in our course. Some professors make a point of integrating EBP, like the faculty teaching me now. I am reviewing articles critically and having to use my critical thinking skills, which are useful for learning EBP". [S13]

Participants talked about working with the research coach, and the teacher gave them a different edge to perceiving EBP. Another student pointed out that "It was meaningful to have a coach-trainee relationship at a different level and to work on case studies that were meaningful to the topic. The teacher was keen on health promotion for type 2 diabetes and providing evidence on the benefits of diet and exercise was a valuable opportunity". [S6]

Some students stated that working through the EBP videos and case studies with the research coach were helpful to understand concepts, and they were encouraged to discuss these case studies considering EBP. Engagement with the research coach allowed students to receive feedback when facilitating discussions in peer groups. Time spent on coaching students depended on individual responsibility and pace to provide a comfortable relationship to work through the case studies. One student said that "from my engagement with the research coach, I tried to understand EBP when I read the research article. It seemed like jargon, but I learnt how it was used in a real-life setting. Having more than one research coach come to help us in the future is important. Having more than one research coach is beneficial in terms of time and effort to learn EBP". [S11]

As students reflected on their thoughts and feelings about the research coach, they shared their sense of responsibility about learning EBP. Some students managed their time to complete the pre-readings, self-reflection, and interaction with the research coach. As quoted by one student, "I have time conflicts that prevent me from meeting the research coach on a one-on-one basis, but I can meet them in the classroom. I have coursework that has timely expectations, and they are seemingly more important to me. Though contact information of the research coach was given to me, I did not know the best time to contact them". [S6]

\section{Theme 3. Knowledge exchange and application of EBP}

Students found good learning behaviours and interest by integrating and synthesizing concepts while engaging in knowledge exchange with the research coach and use of EBP. They explained that they were collecting resources that might be useful to have a research coach for application of EBP in the course. Students built a relationship with the research coach to improve their capabilities of applying EBP. One student revealed that they "have learnt the concepts of EBP that have shaped my skills to expand my learning and interest in pursuing knowledge and understanding of EBP. I want greater integration of EBP discussions, project creation, and research each year such as one overarching EBP project and paper per year with a research coach to help foster research knowledge and critical thinking". [S15]

Another student declared that they "have gained insight into how to use EBP in my clinical questions and search for articles that communicate results. The class material is always EBP focused, EBP driven, and EBP applied; hence, learning and application are difficult. There is a mixed-use of learning activities for our group in class. This learning has been challenging but has provided a rewarding experience. I love learning through research and collecting data from various reputable sources." [S19]

Students perceived knowledge exchange, problem-solving, and integrating EBP concepts kept them motivated, actively engaged in mutual interaction in addition to obtaining detailed feedback on the assignments. Students developed basic literature searches, asking questions, locating evidence, and applying skills to support their assignments. One student commented that they "learnt to assess the appropriate principles of the best practices in EBP. Sifting through lots of information and watching video links was overwhelming and time-consuming in my learning. The teacher provided us with a detailed assignment overview that supported my development of the Population, Intervention, Comparison, Outcome questions to base my research on". [S16]

Another student observed that they "learnt about developing critical thinking, connecting cause and effect, the process of writing a paper, organizing a group project, and what is important when applying EBP with the teacher. I improved this by narrowing my search parameters. I used correct keywords and abbreviations in our research". [S12] Students were immersed in learning EBP by searching for literature, critical analysis, and references.

Another student translated knowledge of EBP to clinical practice, "I think about what I am doing, and if it is the right way. I challenge it more in a clinically questioning format. For example, I am working with a patient with a near-complete acute kidney injury due to overdose (pre-renal cause, overdose on Tylenol due to low health literacy) on fluid intake. Being a student nurse, I used all my knowledge from nursing courses to figure out how to change or modify the patient's trends towards healing. I advocated for 
fluid restriction and strict monitoring of intake, output, blood pressure, lung sounds, and mental status". [S10]

\section{Discussion}

In this study, research coach and student interaction enhanced competency in understanding and knowledge to effectively use and apply EBP in clinical case studies. This study shows the value of the research coach guiding and facilitating learning both within and outside classroom settings to improve coaching. The student responses confirm the motivation and collaboration of the research coach to provide the best practices in EBP and mediate teaching in EBP orientation. The main themes reported were: (1) engaging in active learning and sharing knowledge, (2) guidance and interacting with a research coach, and (3) knowledge and application of EBP. The core themes describe how the research coach facilitated students in critical enquiry, search skills, and evidence to grasp the knowledge of EBP.

This study shows that the implementation of research coaching intervention led students to have mixed feelings of anxiety and excitement to learn EBP, build capacity, and commit themselves to apply EBP. Student motivation and time are crucial in implementing research coach and integration of EBP in group discussions. Student nurses need support to develop their research skills to aid decision-making, develop clinical questions, and search, critique and synthesise research evidence while incorporating preferences to inform their practice. Research coaching was observed to engage students in case study group discussions, and online discussion provides students with learning activities, answers questions, provide feedback, and encourages discussion compared to faculty teaching. Immediate feedback is known to facilitate students' motivation to learn and continuity in learning. The research coach was perceived to be appropriate and relevant to engaging in and using EBP learning materials in peer groups.

The research coach model comprised a traditional face-toface and an online learning (Moodle), which helped participants integrate knowledge and translate research into practice. The study showed that students had positive perceptions of their knowledge and learning through case studies and expressed satisfaction with online discussions. The students expressed the relevance of the practical case studies and of sharing critical dialogues in class. Other studies have shown that participants' attitudes towards EBP are more favourable than their knowledge and competencies, ${ }^{[31]}$ while collaborative learning and clinical research presentations are significant in engaging students with EBP teaching. ${ }^{[32,33]}$ The findings from the current study demonstrate that the research coach model enhances the knowledge of EBP in nursing stu-

Published by Sciedu Press dents. Interactive teaching strategies that aim to obtain sound knowledge and literacy skills are perceived as challenging and time-bound for student nurses.

The research model showed that nursing students experienced motivation and an increased awareness of a greater understanding of the database search strategy, selecting relevant literature, and had an increased level of trust in the research evidence such as EBP. As a platform to facilitate the development of research skills, the research coach indicated the need to conceptualise and contextualise EBP to enable relevant and meaningful learning. Activities that provide students with opportunities to apply concepts in real-world scenarios will prepare them to participate in decision-making using evidence. ${ }^{[34]}$ In Australia and Norway, undergraduate students that participated in research projects related to EBP had positive attitudes towards EBP and were more focused on critical thinking. ${ }^{[35]}$ In Spain, EBP knowledge led to positive changes and were significantly improved in an intervention group and a control group following EBP intervention. ${ }^{[10]}$ EBP assignments could be integrated into courses in a patient care context that reflects students' abilities in making practice decisions. ${ }^{[36]}$

The research coach model showed that students were engaged in understanding EBP, clarifying concepts, and applying problem-solving skills to learning opportunities. This learning encouraged students to question and seek rationale in the application of EBP to clinical experiences. Nursing students have reported enhanced analytical and critical thinking skills from these teaching strategies ${ }^{[37]}$ and have improved their information literacy skills. ${ }^{[38]}$ Furthermore, students who have been involved in oral presentations and journal clubs have found it helpful to analyse and discuss the findings of $\mathrm{EBP}^{[39]}$ and are more likely to improve their EBP knowledge and skills. ${ }^{[13]}$ The current study demonstrated that the research coach model helped students achieve basic knowledge in EBP to translate knowledge. The health and healing course integrated EBP concepts and were perceived as effective when students were provided with an avenue to connect the relationship of EBP concepts to case studies.

In the current study, while second-year nursing students started to learn the concepts of EBP, less emphasis was placed on current application of EBP in clinical practice. These students were searching for evidence by accessing databases that are useful in improving their EBP uptake. The research coach model demonstrated that students could achieve knowledge and meet expectations in the initial application of EBP. Nursing students have significantly higher self-perceived skills and knowledge mean scores. ${ }^{[40]}$ Moreover, attitude, skills, and knowledge towards EBP and access to Internet 
journals have supported students' learning in EBP. ${ }^{[13]}$ Nursing students' increased capability can explain their intention to use and adopt EBP in their future nursing. ${ }^{[3]}$ The study implies that an addition of the research coach is beneficial for facilitating EBP for undergraduate students in the course.

Limitations include the contextual research coach used for a specific class, which may not represent the views of all students and limits the generalisability of the findings. Participants were encouraged to be open and honest about their experiences but may have emphasised their positive experiences. Participants were volunteers who may have been positively inclined towards the opportunity to use a research coach and blending learning. The community of inquiry, personality, and learning styles were not measured. There was no true experimental features of randomization, comparison, repeated measures, efficacy, and evaluation, which limit the ability to attribute a causal role to the activities of the research coach.

\section{Conclusion}

The study found that a research coach can play an important role in nursing students' learning and identifies the critical capabilities in blending learning. Developing a research coach model is a practical teaching approach for undergraduate students to provide guidance and help students improve integration of EBP in practice care settings. Engaging students in meaningful learning that integrates EBP as a powerful teaching tool is associated with improved learning performance. This study adds to the knowledge of blended approaches, EBP, and how research coaches can improve teaching-learning with clinical nurse educators and faculty instructors in undergraduate nursing education. This study suggests that research coach may have assisted to enhance students' preparation to practice EBP by providing leadership opportunities that could facilitate positive learning. Experience with an undergraduate research coach enabled students to develop an appreciation for the link between EBP skills to find, evaluate, and use evidence to improve their nursing practice skills. It is advocated that faculty should facilitate social innovative teaching strategies to become involved in understanding and applying EBP. The research coach model creates a liaison between faculty and students with potential to improve application of inquiry-based learning. Usefulness of the research coach program would have been an interesting angle to pursue in future experimental research studies or randomized control trials.

\section{FUNDING SOURCES}

This grant was supported by Thompson Rivers University Faculty Research Coach No. 210780/19/2018. The sponsors played no role in the design, execution, analysis, data interpretation, writing reports or decision to submit the paper for publication.

\section{ACKNOWLEDGEMENTS}

I would like to acknowledge the support of Matthew Stranach, Educational Technologies, Open Learning, Thompson Rivers University, and a third-year undergraduate research coach.

\section{CONFlicts OF INTEREST Disclosure}

The author declares that there is no conflict of interest.

\section{REFERENCES}

[1] Canadian Association of Schools of Nursing. National nursing education framework. Position statement. 2015.

[2] College of Registered Nurses of British Columbia. Competencies in the context of entry-level registered nurse practice in British Columbia. College of Registered Nurses of British Columbia. 2014. Available from: https://www.crnbc.ca/Registration/Lists/Regist rationResources/375CompetenciesEntrylevelRN.pdf

[3] Labrague LJ, McEnroe-Petitte D, D'Souza MS, et al. Capability beliefs and the intention to adopt evidence-based practices in the future among nursing students: An international study. Journal of Professional Nursing. 2020. https : //doi .org/10.1016/j .prof nurs. 2020.01.006

[4] Fineout-Overholt E, Levin RF, Melnyk BM. Defining mentorship for EBP. Teaching Evidence-based Practice in Nursing. 2013; 3-12.

[5] Malik G, McKenna L, Griffiths D. Envisaging the use of evidencebased practice (EBP): how nurse academics facilitate EBP use in theory and practice across Australian undergraduate programmes.
Journal of Clinical Nursing. 2017; 26(17-18): 2669-2679. https : //doi.org/10.1111/jocn.13705

[6] Kyriakoulis K, Patelarou A, Laliotis A, et al. Educational strategies for teaching evidence-based practice to undergraduate health students: systematic review. Journal of Educational Evaluation for Health Professions. 2016; 13. https://doi.org/10.3352/jeehp.2016.1 3.34

[7] Leach MJ, Hofmeyer A, Bobridge A. The impact of research education on student nurse attitude, skill and uptake of evidence-based practice: a descriptive longitudinal survey. Journal of Clinical Nursing. 2016; 25(1-2): 194-203. https://doi.org/10.1111/jocn .13103

[8] Halabi JO, Hamdan-Mansour A. Attitudes of Jordanian nursing students towards nursing research. Journal of Research in Nursing. 2012; 17(4): 363-373. https://doi.org/10.1177/17449871103797 82

[9] Spencer TD, Detrich R, Slocum TA. Evidence-based practice: A framework for making effective decisions. Education and Treatment of Children. 2012; 35(2): 127-151. https ://doi.org/10.1353/ etc. 2012.0013 
[10] Ruzafa-Martínez M, López-Iborra L, Barranco DA, et al. Effectiveness of an evidence-based practice (EBP) course on the EBP competence of undergraduate nursing students: a quasi-experimental study. Nurse Education Today. 2016; 38: 82-87. https ://doi.org/10.1 016/j.nedt. 2015.12.012

[11] Zeleníková R, Jarošová D. Perception of the effectiveness of evidencebased practice courses by Czech nursing and midwifery students. Central European Journal of Nursing and Midwifery. 2014; 5(4): 169-175. https://doi.org/10.15452/CEJNM. 2014.05.0013

[12] Blackman IR, Giles TM. Can Nursing Students Practice What Is Preached? Factors Impacting Graduating Nurses' Abilities and Achievement to Apply Evidence-Based Practices. Worldviews on Evidence-Based Nursing. 2017; 14(2): 108-117. https://doi .or g/10.1111/wvn. 12205

[13] Labrague LJ, McEnroe-Petitte D, D’Souza MS, et al. A Multicountry Study on Nursing Students' Self-Perceived Competence and Barriers to Evidence-Based Practice. Worldviews Evid Based Nurs. 2019; 16(3): 236-246. https://doi.org/10.1111/wvn. 12364

[14] Johnson N, List-Ivankovic J, Eboh WO, et al. Research and evidencebased practice: Using a blended approach to teaching and learning in undergraduate nurse education. Nurse Education in Practice. 2010; 10(1): 43-47. https://doi.org/10.1016/j.nepr.2009.03.0 12

[15] Burkhart PV, Hall LA. Developing the next generation of nurse scientists. Nurse Educator. 2015; 40(3): 160-162

[16] Malik G, McKenna L, Griffiths D. How do nurse academics value and engage with evidence-based practice across Australia: Findings from a grounded theory study. Nurse Education Today. 2016; 41: 54-59. https://doi.org/10.1016/j.nedt.2016.03.015

[17] Gruber-Page M. The value of mentoring in nursing: An honor and a gift. In Oncology nursing forum. Oncology Nursing Society. 2016; 43(4): 420. https : //doi.org/10.1188/16. oNF . 420-422

[18] McCulloch A, Picard MY, Gregoric C, et al. Informal peer mentoring in early career researchers. International Journal for Researcher Development. 2015.

[19] Van Niewerburgh C. (Ed.). Coaching in education: Getting better results for students, educators, and parents. Routledge. 2018. https://doi.org/10.4324/9780429473036

[20] Won MR, Choi YJ. Undergraduate nursing student mentors' experiences of peer mentoring in Korea: A qualitative analysis. Nurse Education Today. 2017; 51: 8-14. https://doi.org/10.1016/j. nedt.2016.12.023

[21] Benigni M, Petrosky S. Mentoring matters: a toolkit for organizing and operating student advisory programs. R\&L Education. 2011.

[22] Hudson P, Hudson S, Gray B, et al. Learning about being effective mentors: Professional learning communities and mentoring. Procedia-Social and Behavioral Sciences. 2013; 93: 1291-1300. https://doi.org/10.1016/j.sbspro.2013.10.031

[23] Smith J, Nadelson L. Learning for you and learning for me: Mentoring as professional development for mentor teachers. Mentoring \& Tutoring: Partnership in Learning. 2016; 24(1): 59-72. https://doi.org/10.1080/13611267.2016.1165489

[24] Devine M, Meyers R, Houssemand C. How can coaching make a positive impact within educational settings? Procedia-Social and Behavioral Sciences. 2013; 93: 1382-1389. https : //doi .org/10 $.1016 /$ j. sbspro. 2013.10.048

[25] Van Nieuwerburgh C, Barr M. Resources for coaching in education: Useful research and references. 2016.

[26] Fields R. Students' perceptions of an executive coaching intervention: a case study of an enabling education programme. Coaching: An
International Journal of Theory, Research and Practice. 2018; 11(2): 102-116. https://doi.org/10.1080/17521882.2017.140780 5

[27] Green LS, Norrish JM, Vella-Brodrick DA, et al. Enhancing wellbeing and goal striving in senior high school students: Comparing evidence-based coaching and positive psychology interventions. 2014.

[28] Dorrington L, van Nieuwerburgh C. The development of peer coaching skills in primary school children: An exploration of how children respond to feedback. International Journal of Information and Education Technology. 2015; 5(1): 50. https://doi .org/10.7763/IJ IET. 2015.V5. 475

[29] van Nieuwerburgh C, Zacharia C, Luckham E, et al. Coaching students in a secondary school: a case study. In Coaching in Education (pp. 191-198). Routledge. 2018. https ://doi .org/10.4324/97 80429473036-11

[30] Upton D, Upton P. Development of an evidence-based practice questionnaire for nurses. Journal of Advanced Nursing. 2006; 53(4): 454-458. https://doi.org/10.1111/j.1365-2648.20 $06.03739 . \mathrm{x}$

[31] Stichler JF, Fields W, Kim SC, et al. Faculty knowledge, attitudes, and perceived barriers to teaching evidence-based nursing. Journal of Professional Nursing. 2011; 27(2): 92-100. https ://doi.org/ $10.1016 / j$.profnurs . 2010.09.012

[32] Centrella-Nigro AM, Flynn D. Teaching evidence-based practice using a mock trial. The Journal of Continuing Education in Nursing. 2012; 43(12): 566-570. https://doi.org/10.3928/00220124 $-20120917-27$

[33] Finotto S, Carpanoni M, Turroni EC, et al. Teaching evidence-based practice: developing a curriculum model to foster evidence-based practice in undergraduate student nurses. Nurse Education in Practice. 2013; 13(5): 459-465. https ://doi.org/10.1016/j.nepr. 201 3.03 .021

[34] Chang HC, Jones MK, Russell C. Exploring attitudes and barriers toward the use of evidence-based nursing among nurse managers in Taiwanese residential aged care facilities. Journal of Gerontological Nursing. 2013; 39(2): 36-42. https://doi.org/10.3928/0098 9134-20130110-02

[35] André B, Aune AG, Brænd JA. Embedding evidence-based practice among nursing undergraduates: results from a pilot study. Nurse Education in Practice. 2016; 18: 30-35. https ://doi.org/10.1 016/j.nepr.2016.03.004

[36] Moch SD, Quinn-Lee L, Gallegos C, et al. Navigating evidence-based practice projects: the faculty role. Nursing Education Perspectives. 2015; 36(2): 128-130. https://doi .org/10.5480/12-1014.1

[37] Naber J, Wyatt TH. The effect of reflective writing interventions on the critical thinking skills and dispositions of baccalaureate nursing students. Nurse Education Today. 2014; 34(1): 67-72. https : //doi.org/10.1016/j.nedt.2013.04.002

[38] Travis TA. From the classroom to the boardroom: The impact of information literacy instruction on workplace research skills. Education Libraries. 2017; 34(2): 19-31. https://doi.org/10.26443 /el.v34i2.308

[39] Horntvedt MET, Nordsteien A, Fermann T, et al. Strategies for teaching evidence-based practice in nursing education: a thematic literature review. BMC Medical Education. 2018; 18(1): 172. https : //doi.org/10.1186/s12909-018-1278-z

[40] Labrague LJ, McEnroe-Pettite D, Tsaras K, et al. Predictors of evidence-based practice knowledge, skills, and attitudes among nursing students. Nurs Forum. 2019; 54(2): 238-245. https ://doi .or $\mathrm{g} / 10.1111 /$ nuf .12323 